\title{
Territorialidade e desastre: a gestão dos desastres no Brasil com base no estudo de caso da Defesa Civil em Santa Catarina
}

\author{
Territoriality and disaster: the management of disasters in \\ Brazil based on case study of Civil Defense in Santa Catarina
}

Késia Joner [a] [D, Maria Roseli Rossi Avila [b] [D, Marcos Antonio Mattedi [b] [D]

[a] Universidade Federal de Santa Catarina (UFSC), Programa de Pós-graduação em Serviço Social (PPGSS),

Florianópolis, SC, Brasil

[b] Universidade Regional de Blumenau (FURB), Programa de Pós-graduação em Desenvolvimento Regional (PPGDR), Blumenau, SC, Brasil

Como citar: Joner, K., Avila, M. R. R., \& Mattedi, M. A. (2021). Territorialidade e desastre: a gestão dos desastres no Brasil com base no estudo de caso da Defesa Civil em Santa Catarina. urbe. Revista Brasileira de Gestão Urbana, v.13, e20200061. https://doi.org/10.1590/2175-3369.013.e20200061

\section{Resumo}

O artigo aborda a gestão dos desastres a partir do estudo de caso da Defesa Civil de Santa Catarina. Argumenta que quanto maior a centralização e tecnificação, menor a coordenação e mais burocrática a gestão. A burocratização resulta em uma atuação mais voltada à Gestão dos Desastres (GD) do que à Gestão do Risco de Desastres (GRD) como preconizam o Marco de Ação de Hyogo e o Marco de Sendai. Com a centralização e a tecnificação, fases importantes da GRD como a participação social e comunitária nos processos decisórios são ignoradas, bem como o conhecimento científico e os saberes locais. Estes últimos, premissas importantes para a GRD pois atuam no fortalecimento da resiliência de um sistema ou comunidade.

Palavras-chave: Desastre. Gestão. Defesa Civil. Santa Catarina.

\section{Abstract}

The article addresses the issue of disaster management from the case study of Civil Defense of Santa Catarina. It argues that the greater the centralization and technification, the less coordinated and more bureaucratic management becomes. Bureaucratization leads to Disaster Management (DM) instead of Disasters Risk Management (DRM) as advocated by the Hyogo Mark for Action and the Sendai Mark. Important phases of DRM such as community participation and decision-making processes are ignored, as well as the scientific knowledge and local knowledge. These knowledges, important premises for DRM since they act in the resilience reinforcement of a system or community.

Keywords: Disaster. Management. Civil Defense. Santa Catarina. 


\section{Introdução'}

O número de ocorrências e os gastos públicos com desastres socioambientais aumentam no mundo inteiro (ONU, 2015). Também o impacto dos desastres sobre as populações ocorre de forma cada vez mais avassaladora (Amin \& Goldstein, 2008). Informações do Em-Dat - plataforma que contém dados da ocorrência de mais de 22.000 grandes desastres desde 1900, confirmam os dados (Guha-Sapir, et al., 2020). Conforme a plataforma (Guha-Sapir et al., 2015), em 1970 os números apontavam cerca de 80 ocorrências/ano. Em 2008, esse número aumentou para 400 ocorrências/ano e, em 38 anos, o aumento é significativo. Também os prejuízos aumentaram, em 1975, perfaziam cinco bilhões de dólares. Em 2008, já somavam 180 bilhões e em 2015, 300 bilhões. Hoje as preocupações com os desastres são globais e foram incorporadas na agenda governamental e as pesquisas avançaram.

Apesar dos avanços, polêmicas também se fazem presentes na discussão sobre os estudos e a gestão dos desastres. Perry \& Quarantelli (2005) apontaram falta de consenso e disputas conceituais acirradas entre os estudos da área social e técnica sobre os desastres. Em pauta a compreensão dos desastres a partir da abordagem da ameaça ou da vulnerabilidade (campo cognitivo) e a oposição entre as medidas de preparação e recuperação e entre a centralidade estatal e a organização comunitária na gestão (campo político). Assim, torna-se imprescindível voltar os olhos à história da pesquisa sobre os desastres, cujo início se deu em 1920 quando dois navios colidiram no porto de Halifax, no Canadá, causando uma forte explosão. Preocupado com os danos ao desenvolvimento da cidade, um estudante de doutorado chamado Prince decidiu estudar o desastre.

Prince chegou à conclusão de que aquele incidente não prejudicou o desenvolvimento citadino (Prince, 1920). As pesquisas continuaram e, doze anos mais tarde, outro pesquisador fez uma constatação importante: Carr (1932) percebeu que os desastres diferem entre si no tempo e no espaço. Temporalmente podem ser instantâneos ou progressivos e, espacialmente, focalizados ou difusos. Estudiosos daquela época entendiam os desastres como patologias sociais e consideravam seu impacto sobre a população como oportunidades de estudos. Nos Estados Unidos, Gilbert White (1974) iniciou, em 1945, estudos sobre as perdas e danos causados por enchentes. White buscou provar que as medidas estruturais implantadas pelo governo não diminuíam os danos ao país causados pelas enchentes.

O pesquisador incluiu a variável humana em seus estudos sobre a problemática. Com essa inserção, o território (espaço), as áreas de perigo e a percepção da população sobre o evento passaram a ter importância. Também o campo político ganhou seu espaço, pois os processos de escolha das medidas a serem tomadas e os efeitos das políticas públicas sobre as medidas escolhidas também passaram a fazer parte dos estudos (White, 1974). 0 pesquisador queria saber de que forma o ser humano se ajustaria aos riscos dos desastres socioambientais, como compreendia esse processo e no que seu ajustamento implicaria para as políticas públicas locais (White, 1973). A partir disso, a relação do homem com o meio social e a natureza é inserida no centro dos estudos sobre os desastres. White passou a estudar, em 1956, fenômenos como terremotos, erupções, furacões e secas. Essa inclusão gerou o campo de estudos denominado Hazards (Mattedi \& Butzke, 2001).

A palavra significa perigo ou ameaça. Conforme Mattedi \& Butzke (2001, p. 03), Hazards podem ser considerados "fenômenos como, por exemplo, avalanches, terremotos, erupções vulcânicas, ciclones, deslizamentos, tornados, enchentes, epidemias, pragas, fome e muitos outros". No entanto, no estudo dos Hazards os indivíduos impactados eram vistos como "vítimas 'desafortunadas' que possuíam uma baixa capacidade de reação" ao fenômeno (Mattedi \& Butzke, 2001, p. 4). White (1973) definiu os Hazards como a interação indivíduo-natureza regida pelo ajustamento aos eventos. Significa que o foco das ações recai sobre as dimensões físicas do evento e na ameaça que ele significa para o ser humano (Montz \& Tobin,

\footnotetext{
1 Este trabalho tem o apoio da ACAFE. Protocolo EFAP 1435183.
} 
2011). Para Mattedi \& Butzke (2001, p. 5), o estudo objetiva compreender como os humanos se comportam diante do evento e "estabelecer procedimentos de predição, proteção e resposta" aos mesmos.

Mais tarde, os estudos sobre os desastres passaram a ter uma abordagem sociológica. Esta considera o contexto social do evento, a população e o impacto do fenômeno sobre ela. A abordagem dos Disasters foca na dimensão física e na dimensão social dos desastres com ênfase na social. Ganha importância a tríade: a) agente deflagrador do desastre; b) agente receptor do impacto; e c) resposta dada ao evento. No entanto, a compreensão dessa tríade passa por três níveis de compreensão importantes: 1) a informação sobre a construção social dos desastres; 2) a intensificação de pesquisadores na área; e 3) a gestão cada vez mais sofisticada, com desastres cada vez mais destrutivos (Avila \& Mattedi, 2017). Esse último, discorre sobre o tema deste artigo: a gestão comunitária e burocrática dos desastres.

Existe uma relação intrínseca entre a capacidade social de gerir o evento e a frequência, o potencial de destruição e como se dá o impacto do desastre (Wenger, 1978). E é essa relação intrínseca que demonstra que a resposta dada ao evento não depende apenas do processo geofísico do evento, mas também do ponto de vista dos indivíduos impactados por ele. Por isso, é o tipo de sociedade, os indivíduos e a posição que nela ocupam que determina o quão grave é o impacto do desastre (Quarantelli, 1994). A palavra Desastre tanto pode se referir a um único evento ou a uma série deles e "tem sido empregada para caracterização de todo tipo de infortúnio súbito, inesperado ou extraordinário" (Mattedi \& Butzke, 2001, p. 9). Desastres são vetores de mudança na rotina e na funcionalidade da sociedade e podem ser causados tanto por meios naturais como pelo homem, pressupondo uma relação entre a sociedade e a natureza que evidencia sua construção social.

Em 1970, os pesquisadores passam a considerar os desastres como fenômenos que se concentram no espaço e no tempo em que a estrutura social é impactada pelo evento (Pelanda, 1981). É nesse período que surgem Quarantelli \& Dynes (1977) que passaram a estudar os desastres a partir da organização social e do impacto dos eventos sobre ela. Os autores criaram sete formas de analisar e interpretar os desastres: 1) preocupar-se mais com a organização social do que com a psicologia social; 2) na análise, priorizar grupos ao invés de indivíduos; 3) dar ênfase à noção de sistema nas pesquisas; 4) ajustamento entre as abordagens do comportamento coletivo e as organizações complexas ao estudar o comportamento coletivo nas crises; 5) estudos do período de pré-impacto dos desastres devem resultar em mudanças no pós-impacto; 6) dar ênfase nas consequências funcionais e disfuncionais de longo prazo; e 7) criar modelos teóricos para estudos futuros.

Os autores afirmam que quanto menor a fase pré-impacto (Tempo 1) do desastre, maior será a destruição na fase pós-impacto (Tempo 2). Significa que a destruição que ocorre no Tempo 1 do evento é explicada pelas condições sociais existentes no Tempo 2. Essa abordagem trouxe mudanças nos estudos, pois possibilitou respostas em duas áreas importantes: na institucionalização das pesquisas e da produção científica e na formulação e implantação de políticas públicas e das ações governamentais (Quarantelli \& Dynes, 1977). Com essas e outras mudanças que ocorreram no estudo dos desastres, um novo paradigma foi incorporado às pesquisas e à gestão: a noção de vulnerabilidade (Gall et al., 2015). Essa inclusão representou uma mudança radical na forma de pensar as relações sociedade/natureza e na elaboração e implantação das estratégias de gestão dos desastres (Marandola \& D'antona, 2014).

$\mathrm{O}$ artigo fundamenta-se, metodologicamente, numa abordagem bibliográfica de cunho qualitativo, teórico-empírica e exploratória. Resulta de pesquisas sobre a gestão dos desastres no Brasil com base no estudo de caso das enchentes em Santa Catarina, queimadas em Rondônia e seca no Piauí (Aprovada pelo Comitê de Ética em 26/07/2019 - Parecer no: 3.472.193). Nesse universo, buscou-se investigar as relações entre Desenvolvimento Regional e Território, como são produzidos e se reproduzem os desastres, risco e vulnerabilidade. Para isso, estudou-se a história de Defesa Civil no mundo e no Brasil. As pesquisas resultaram na criação de um banco de dados sobre a instituição, que servirá de subsídio para estudos futuros e produção científica na área dos desastres. Para fins deste artigo, focamos na análise da instituição responsável pela gestão dos desastres em Santa Catarina. 
O texto apresenta uma análise da gestão dos desastres no Brasil a partir do estudo de caso da Defesa Civil (DC) de Santa Catarina (SC). Como tese, a gestão comunitária e a gestão burocrática dos desastres. 0 artigo foi dividido em cinco partes, sendo que a primeira traz um histórico sobre os desastres, o início das pesquisas, os primeiros estudiosos, suas teorias e concepções. A segunda, discute a gestão dos desastres socioambientais, apresentando diversos modelos de Gestão de Desastres (GD) e Gestão do Risco de Desastres (GRD) e seus devidos autores. A terceira parte fala da DC de SC, sua história, leis e estrutura de organização. Na quarta, o texto traz uma análise da DC de SC a partir de sua institucionalização no Estado. Discute a forma como atua, a relação com outras instituições e sua estrutura atual. Argumenta que quanto mais gestão, mais centralização e tecnificação, resultando no aprofundamento da gestão burocrática dos desastres. Na quinta parte, as considerações finais dos autores.

\section{A gestão de desastres}

Ao discutirmos desastres na região faz-se necessário analisar os fatores endógenos e exógenos, bem como as questões materiais e simbólicas dos processos de desenvolvimento desta região. Compreender como o desastre foi construído e como é tratado ou gestado no território. A relação entre três fatores: desenvolvimento, região e desastres, nos permite compreender a construção social desta região com relação ao fenômeno que a atinge. Ou seja, a ocorrência de um fenômeno sobre determinada região deixa consequências materiais e simbólicas à população atingida, altera a relação homem-natureza e é a partir do impacto sofrido que se dará a ação e o trato da questão (Burton et al., 1993). Para compreender o processo histórico da produção do risco e vulnerabilidade a desastres em determinada região há um conjunto de fatores a se considerar, aspectos geofísicos e espaciais, os padrões de ocupação e desenvolvimento do território e como se dá a gestão.

Ao longo do tempo, a gestão dos desastres passou por várias fases. Vimos inicialmente que durante muito tempo o foco estava centrado no pós-impacto do desastre, nas situações de emergência. A partir de novos modelos de gestão o foco mudou para a fase pré-impacto do evento. Hoje existem duas formas de atuar na gestão dos desastres: 1) a Gestão dos Desastres (GD) e 2) a Gestão de Risco de Desastres (GRD). A primeira, atua na gestão da crise e é muito utilizada pelo Estado para gerir as situações de emergência no pós-impacto. A segunda, traz como premissas a participação da sociedade civil e da comunidade científica na gestão e atua no pré-desastre. 0 foco na emergência, ou seja, "A intensificação da gestão da crise recebeu o protagonismo estatal que propiciou a centralidade do Estado e das políticas públicas. No entanto, a atuação do Estado na área é centralizadora" (Avila \& Mattedi, 2017, p. 349).

A Gestão de Desastres (GD) atua nas fases pré e pós-impacto, ou seja, nas ações de preparação, mitigação e prevenção (Asghar et al., 2011). Essa fase é denominada de fase de Redução de Risco de Desastres (RRD) e tem como premissas a resposta ao impacto sofrido pelo evento, bem como a recuperação dos danos e a possível retomada do desenvolvimento comunitário. Segundo Albtoush et al. (2011), existem vários modelos de GD, como o Modelo de Expansão e Modelo de Contração, o Modelo de Kimberly, o Modelo de Tuscaloosa, o Modelo de Manitoba ou o Modelo Integrado. Mas os principais modelos de GD são o Modelo Tradicional ou Modelo Linear (também denominado de modelo Clássico) e o Modelo de Kelly ou Modelo Circular (Figura 1). A GD possui características semelhantes à GRD, no entanto sua atuação é desarticulada, centralizada e não integrada entre as fases. 


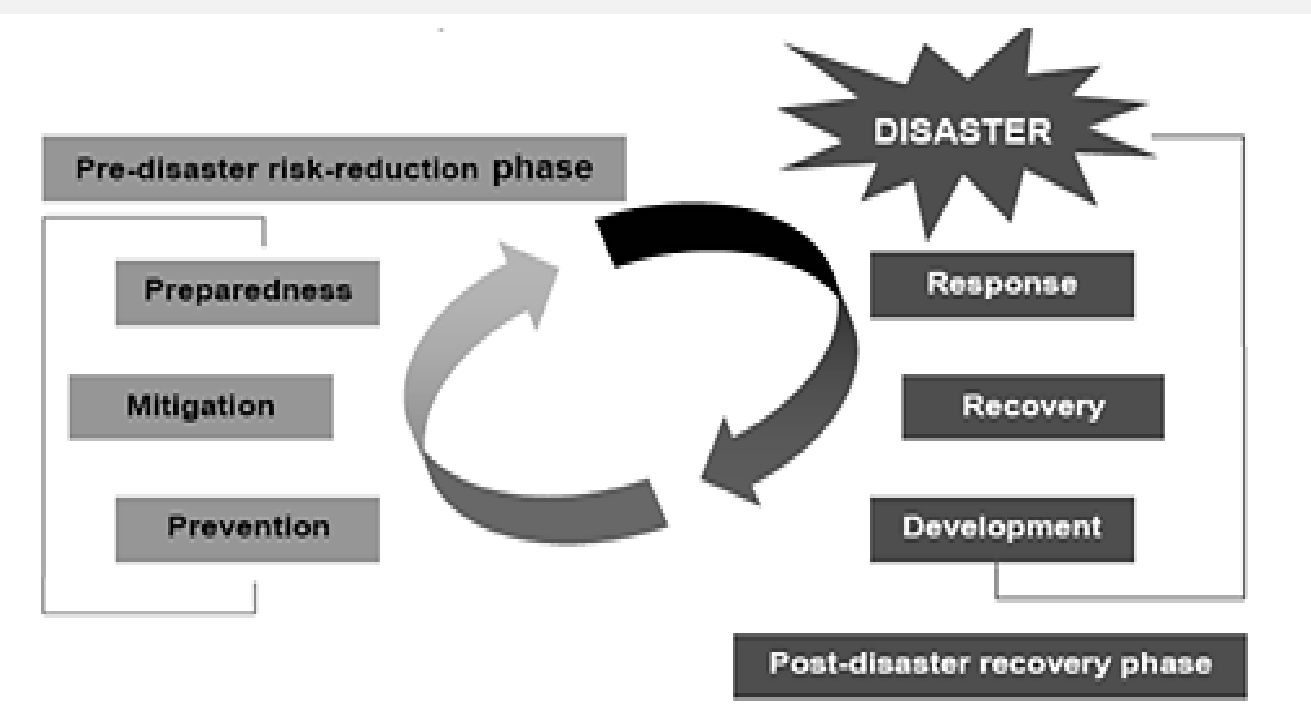

(a)

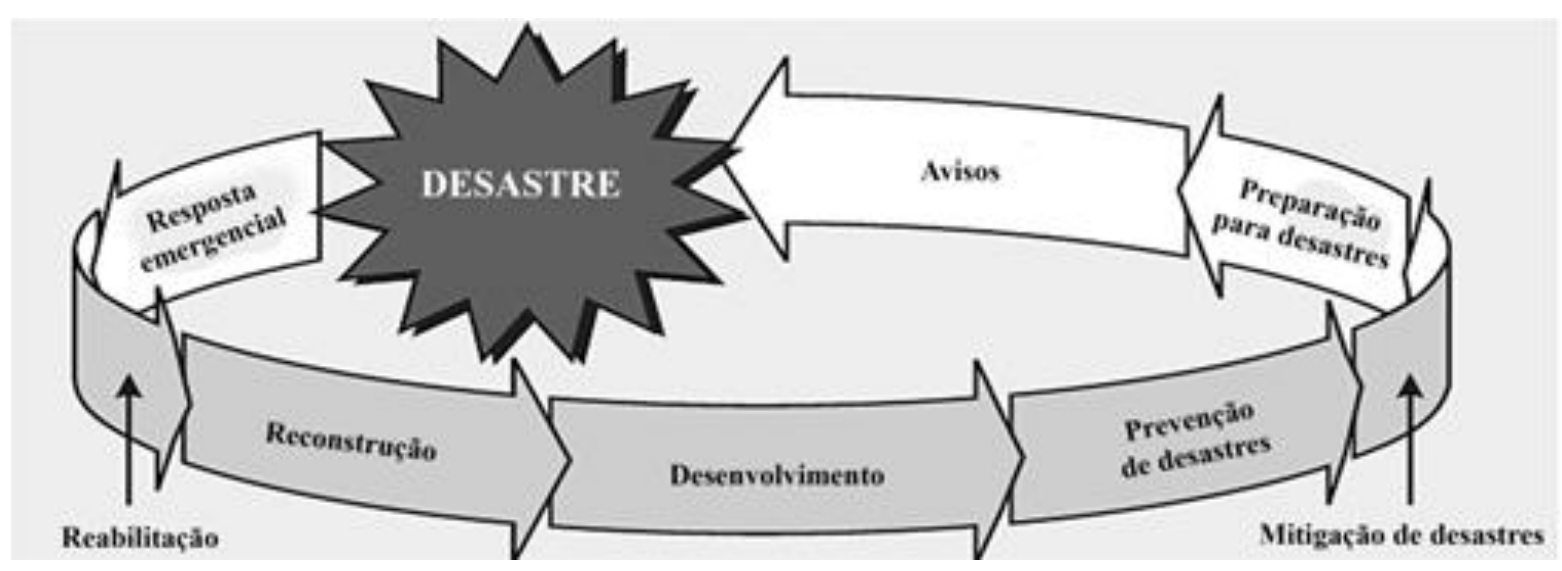

(b)

Figura 1 - Principais Modelos de Gestão dos Desastres (GD): (a) Modelo Tradicional ou Linear de Gestão; (b) Modelo Circular de Gestão (ou Modelo de Kelly). Fonte: Albtoush et al. (2011, p. 55-56).

O Modelo Tradicional ou Linear mantém a ênfase nas fases pré e pós-impacto e apresenta dificuldades de integração entre as informações e o processo decisório, que é extremamente centralizado. Existe uma dicotomia entre as fases, pois o momento de crise ou emergência (fase trans) não é considerado (Albtoush et al., 2011). Já o Modelo Circular tem oito fases, reduz a complexidade dos desastres e considera a natureza não-linear dos eventos. Conforme Avila \& Mattedi (2017, p. 350), este modelo "considera o momento de crise (fase trans) e permite compreender os desastres como um processo integrado". Os modelos de GD têm a função específica de avaliar o risco ou ameaça (hazard) e enviar dados à gestão para que esta atue de forma eficiente. Mas, por atuarem em duas fases, dicotomicamente, os modelos de GD não conseguem integrar as fases e esse acaba sendo o seu maior problema.

A década de 1990 foi declarada pela Organização das Nações Unidas (ONU) a Década Internacional para a Redução de Desastres (International Decade for Natural Disaster Reduction - IDNDR). Foi o início da Gestão de Risco de Desastres no mundo. Foram realizadas três conferências (Yokohama, Kobe e Sendai) que elencaram prioridades e estratégias para atingir os objetivos deliberados. Kobe gerou o Marco de Ação de Hyogo (ISDR, 2005-2015), objetivando reduzir vulnerabilidades locais, aumentar a resiliência das comunidades e diminuir perdas e danos sofridos com o impacto (ONU, 2005). Em 2015, foi realizada em Sendai (Japão) a III Conferência Mundial para Redução do risco de Desastres. Dessa conferência resultou o documento denominado Marco de Sendai para a Redução do Risco de Desastres (2015-2030) que, com o 
Marco de Hyogo mudou o "marco referencial adotado até então de gestão dos desastres (GD) para gestão do risco de desastres (GRD)" (Avila \& Mattedi, 2017, p. 344).

O Marco de Sendai prevê a "Redução substancial nos riscos de desastres e nas perdas de vidas, meios de subsistência e saúde, bem como de ativos econômicos, físicos, sociais, culturais e ambientais de pessoas, empresas, comunidades e países" (ONU, 2015). As mudanças propostas são conceituais, pois direcionam o foco da gestão para a fase pré-impacto do desastre, privilegiando a prevenção e a mitigação do risco. Conforme Narváez et al. (2009), o foco recai sobre a "probabilidade" de perdas e danos redirecionando à ação. É uma mudança estrutural, pois compreende-se que o risco é construído socialmente e atua-se com a participação social e comunitária. 0 objetivo central da GRD é atuar de forma integrada, através de políticas e estratégias que envolvam o estado, a comunidade e os indivíduos. Os níveis se ampliam (Territorial: global, regional e local; Setorial: internacional, federal, estadual e municipal).

Na GRD existem dois modelos principais de gestão: o Modelo Integrado ou Global criado por Lavell (Asghar et al., 2011) e o Sistema Hierárquico de Gerenciamento de Emergências (HSEM - sigla em inglês) de Albtoush et al. (2011). O Modelo Integrado ou Global de Gestão possui seis processos importantes: "1) generar conocimiento sobre el riesgo de desastres en sus diferentes ámbitos, 2) prevenir el riesgo futuro, 3) reducir el riesgo existente, 4) preparar la respuesta, 5) responder y rehabilitar, y 6) recuperar y reconstruir" (Narváez et al., 2009, p. 62). Já o "HSM introduz uma melhoria em relação aos modelos existentes até então. Possui seis componentes principais, o que o identifica muito com os seis processos do modelo integrado: planejamento estratégico, avaliação de risco e perigo, Gestão de Risco (GR), Gestão de Desastres (GD), monitoramento e avaliação" (Avila \& Mattedi, 2017, p. 352).

Os dois modelos possuem características similares com os modelos de governança policêntrica, que enfatizam a multiplicidade e a atuação autônoma, conjunta e sobreposta em diversos níveis de gestão (governos locais, regionais, etc.) e diferentes espaços como empresas, famílias, etc. (Ostrom, 2010). A Policentralidade estimula a reciprocidade e cooperação entre os níveis, permite convergências, diálogo, processos decisivos e execução de ações entre instituições, espaços ou atores sociais envolvidos (Ostrom, 1999). Essa convergência ocorre entre diferentes unidades de poder, entre governos e comunidades locais, no face a face entre cidadãos, valorando saberes e a comunicação mútua (Walker et al., 2000). 0 modelo apresenta mecanismos de resolução de conflitos por consensos, pois enfatiza a confiança, a reciprocidade e a cooperação entre os atores sociais por meio de soluções de auto-organização da gestão pública em níveis local e regional (Ostrom, 2010).

Essas características são inerentes aos dois modelos que se fundamentam em três fases: 1) identificação do risco, 2) redução do risco e 3) gestão do desastre. Assim, preenchem as lacunas deixadas pelos modelos que existiam até então. Diferentemente dos modelos de GD, os modelos da GRD abrangem as três fases de um desastre: pré, trans e pós-impacto. Além disso, os modelos de GRD conseguem trabalhar com a complexidade das situações que possam surgir em cada fase. Para os autores, o caráter dinâmico, multidimensional, multidisciplinar e multi-interdependente deve estar presente em todo processo de gestão, em seus diferentes contextos. A partir disso e pensando no caráter multidirecional, multissignificativo (Mattedi, 2015), a inter e a transciplinaridade que garantem a participação social e comunitária na gestão, Avila \& Mattedi (2017) criaram o Modelo Multidimensional de Gestão de Risco de Desastres (MMGRD) explicitado na Figura 2. 


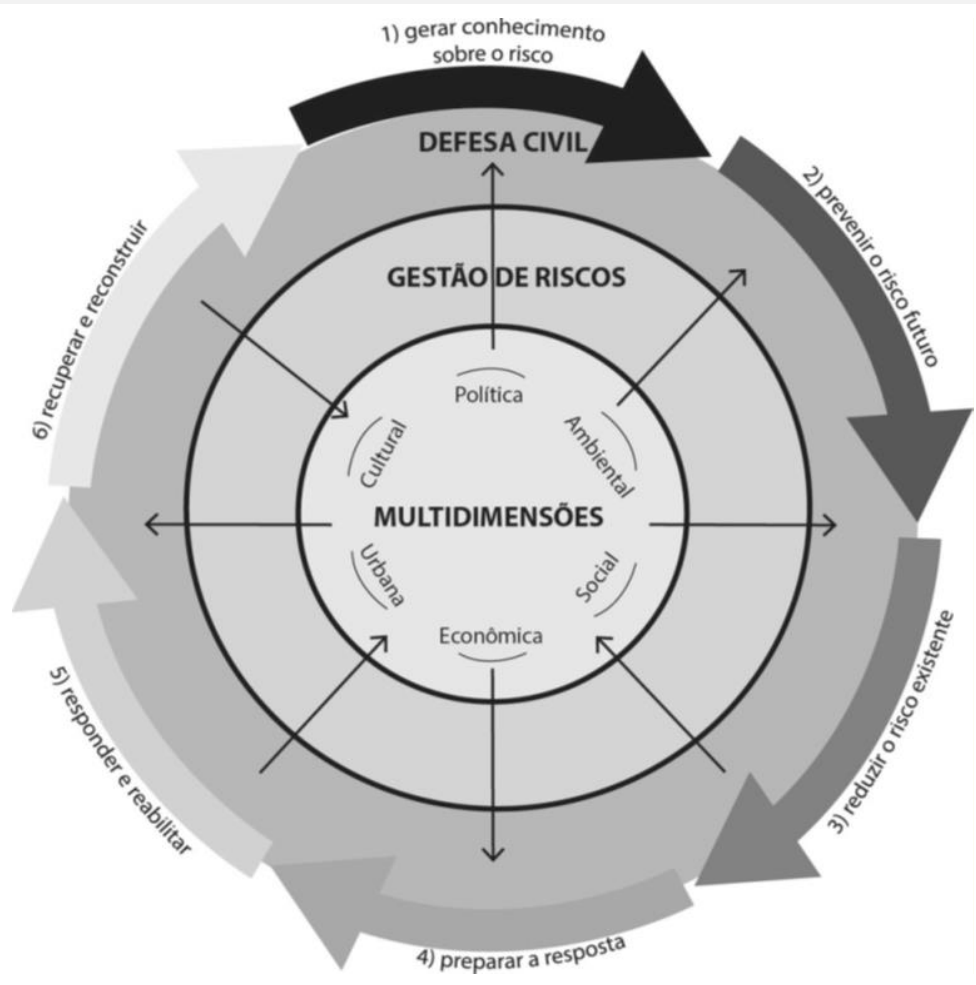

Figura 2 - Modelo Multidimensional de Gestão de Risco de Desastres. Fonte: Avila \& Mattedi (2017, p. 352).

Os Modelos Integrado, HSEM e MMGRD garantem a participação social na gestão, premissa da GRD. Um modelo de GRD considera os atores sociais "e a interdependência entre as dimensões gestoras, suas ações e seu processo de continuidade e não linearidade de gestão" (Avila \& Mattedi, 2017, p. 352). A participação social compreende o envolvimento da comunidade na gestão, a consideração dos saberes locais e científicos, a vulnerabilidade do território e a interação entre os níveis de gestão. 0 Marco de Sendai define parâmetros para a GRD enfrentar os desafios atuais: monitoramento (melhorar os sistemas de alerta), avaliação e compreensão do risco; compartilhar as informações entre os diferentes setores e níveis de gestão; fortalecer a governança do risco e a atuação em rede; investir em pesquisas, resiliência econômica, social, de saúde, cultural e educacional de pessoas, comunidade e no meio ambiente.

\section{A Defesa Civil em SC}

A criação da defesa civil em Santa Catarina data de 1973. A Lei no 4.841 foi promulgada no dia 18 de maio de 1973, no governo de Colombo Machado Salles. Dentre outras providências, estabelece a Coordenadoria Estadual de Defesa Civil (Cedec) e organiza a DC no estado. Ainda em 1973, são instituídas três Comissões Municipais de Defesa Civil (Comdec). No dia 23 de maio daquele ano, conforme DC Itajaí $(s / d)$, foi instituída a primeira Comdec em Itajaí, SC . No entanto, o Conselho não se reunia, pois os desastres não eram frequentes. O Decreto no 253 (1973) instituiu a Comdec em Tubarão, no dia 16 de outubro e em 20 de dezembro, foi instituída a Comissão em Blumenau, por meio da Lei no 1.981 (1973). A Lei afirmava que a Comissão era responsável por acompanhar os eventos adversos, elaborar planos e sugerir medidas frente aos desastres (DC Blumenau, $s / d$ ). Nos três municípios a Comissão desempenhava papel semelhante.

0 prefeito de Tubarão, Irmoto José Feuerschuette, por meio do Decreto no 253, organizou a Comissão Municipal de Defesa Civil no município. Assim como Itajaí (primeira Comdec do estado) e mais tarde Blumenau (terceira Comdec), a Comissão em Tubarão — segunda Comdec — foi a responsável por gerir as ações de prevenção e de enfrentamento aos desastres. Poucos meses após a organização da Comdec em Tubarão, o Sul de Santa Catarina foi atingido por um dos maiores desastres ocorridos no estado e em março de 1974, Tubarão foi assolada pela enchente. Registros apontam o nível do rio Tubarão acima de dez metros. Até hoje não há uma lista oficial do total de vítimas fatais do evento. Os números levantados apontam 199 
mortes. Frente à situação, o prefeito declarou, por meio do Decreto no 267, de 24 de março de 1974, estado de calamidade pública no município (Assunção, 2014).

Desde a colonização, em 1850, o Vale do Itajaí sofre inundações. Em 1983, Blumenau ficou inundada por mais de quatro semanas. As chuvas, em 1984, duraram menos tempo, contudo, o rio Itajaí Açu atingiu um nível maior do que em 1983. Dada à problemática, em 1989 cria-se, em Blumenau, um Departamento da Defesa Civil. Assim, o município passa a dispor de mais este auxílio frente aos eventos. No ano seguinte, criou-se o Fundo Estadual de Defesa Civil (Fundec), que teve seu nome mudado para Fundo Estadual de Proteção e Defesa Civil (Funpdec) pela Lei no 16.418, de 24 de julho de 2014. Dentre outras funções, destinase a gerir os recursos financeiros para as ações de prevenção, de socorro e de assistência emergencial às vítimas de desastres (Assembleia Legislativa de Santa Catarina, 2014).

Em 1991, através da fusão entre Empasc ${ }^{2}$ e Acaresc ${ }^{3}$, cria-se a Empresa de Pesquisa Agropecuária e Extensão Rural de Santa Catarina (Epagri). Trata-se de uma empresa pública, vinculada ao Governo do estado. É a responsável pela rede de monitoramento hidrometeorológico, pesquisas agrometeorológicas e demais temas relacionados que sempre foram disponibilizadas para a comunidade e para a Defesa Civil catarinenses (Vieira, 2019). Seis anos após este marco, em 1997, o estado foi atingido pelo fenômeno $E l$ Niño. Em outubro daquele ano, ocorreram enxurradas, enchentes, vendavais e deslizamentos em 29 municípios catarinenses. Mais de 8.700 pessoas ficaram desabrigadas e duas mortes foram contabilizadas (Herrmann et al., $s / d$ ).

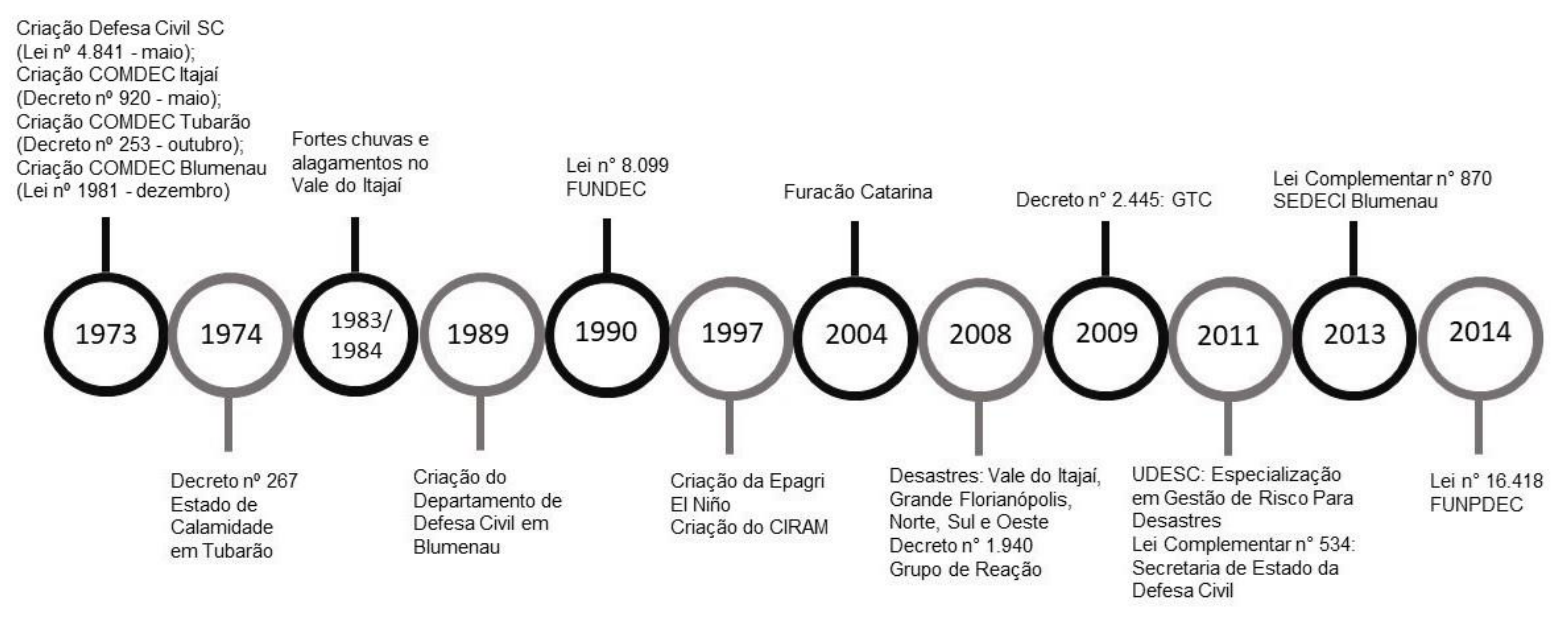

Figura 3 - Linha do Tempo da Defesa Civil em Santa Catarina. Fonte: Joner (2019), com base em dados do CEPED.

Em 14 de julho de 1997, o Centro de Informações de Recursos Ambientais e de Hidrometeorologia de Santa Catarina (Ciram) foi criado. A criação "visou dotar o Estado de Santa Catarina de uma estrutura para a identificação e monitoramento dos recursos naturais e ambientais e a disponibilização de produtos de agrometeorologia" (Massignam et al., 2016, p. 56). Objetiva prestar serviços especializados através da integração de dados e informações dos recursos ambientais. Em 27 de março de 2004, ventos de $180 \mathrm{~km} / \mathrm{h}$ atingiram a costa do Atlântico Sul. Santa Catarina e Rio Grande do Sul foram acometidos pelo "Furacão Catarina". Registra-se que quarenta municípios foram impactados no Sul e litoral Norte de SC. Foi o primeiro furacão registrado no estado. Dados do Ceped (2015) apontam que cerca de 33 mil pessoas ficaram desabrigadas, 518 feridas e 11 perderam a vida com a passagem do ciclone.

Novembro de 2008 marcou para sempre a história de Santa Catarina. Inundações e deslizamentos impactaram a vida e a natureza nos municípios catarinenses. Quatorze municípios receberam decreto de estado de calamidade pública. Mais de sessenta cidades estavam em situação de emergência. A maior parte das vítimas fatais, cerca de 85\%, estavam nos municípios de Ilhota, Blumenau, Gaspar, Jaraguá do Sul e Luís Alves. Mais de 1,5 milhões de pessoas foram atingidas. 135 mortes, 4,75 bilhões de reais de perdas e danos

\footnotetext{
2 Empresa Catarinense de Pesquisa Agropecuária.

${ }^{3}$ Associação de Crédito e Assistência Rural do Estado de Santa Catarina (hoje extinta).
} 
aos cofres públicos, três mil deslizamentos apenas em Blumenau. Enchentes, inundações e deslizamentos no Vale do Itajaí, na Grande Florianópolis, e nas regiões Oeste, Norte e Sul do estado. Mais de setenta e oito mil pessoas ficaram desalojadas. Casas, edifícios, escolas, unidades públicas de saúde e educação, fábricas, lojas, mercados e plantações foram destruídas (Zenatti \& Souza, 2009).

No dia 3 de dezembro de 2008 o governo de Luiz Henrique da Silveira, instituiu o Grupo de Reação à situação de emergência e ao estado de calamidade pública nos municípios do estado. Compete ao Grupo assessorar o governo no que concerne à definição de prioridades referentes à reconstrução dos danos causados pelos eventos (Zenatti \& Souza, 2009). Em 13 de julho de 2009 cria-se o Grupo Técnico-Científico (GTC). Associado ao Grupo de Reação, o GTC pesquisa e estuda, de maneira multidisciplinar, as possibilidades de minimizar os riscos de desastres socioambientais em Santa Catarina. Objetiva assessorar o governo do estado na "avaliação e identificação das causas, efeitos e adoção de medidas preventivas às catástrofes naturais" (Queiroz, 2009, p. 3). Em 2011, conforme (CNM, 2015), inicia-se o curso de Especialização em Gestão de Riscos para Desastres, na Universidade do Estado de Santa Catarina (Udesc).

Ainda no ano de 2011, no dia 20 de abril, através da Lei Complementar no 534 (2011), instituiu-se a Secretaria de Estado da Defesa Civil, no estado (Panceri, 2019). Anteriormente, tratava-se do Departamento Estadual de Defesa Civil (DEDC), então vinculado à Secretaria Executiva da Justiça e Cidadania e à Secretaria de Estado da Segurança Pública e Defesa do Cidadão. No ano seguinte, ocorre a estruturação da Secretaria, a captação de recursos para a primeira fase de sobre-elevação de barragens e os primeiros estudos para implantação do Radar do Vale no município de Lontras. Em 2013, no município de Blumenau, é criada a Secretaria Municipal de Defesa do Cidadão (Sedeci), através da Lei Complementar no 870 (2013), de 01 de janeiro de 2013. Integram a Secretaria as diretorias do AlertaBlu, da Defesa Civil, da Geologia, Análise e Riscos Naturais, de Projetos e de Políticas Integradas de Segurança (DC Blumenau, $s / d$ ).

Em 2014 foi elaborado o Plano Plurianual da Secretaria de Defesa Civil em Santa Catarina. No mês de julho deste mesmo ano, o Radar do Vale, no município de Lontras, foi ativado. Em 19 de janeiro de 2015, o governador do estado, João Raimundo Colombo, sancionou a Lei no 16.601 , legislação que dispõe sobre a incorporação nos Planos Diretores municipais dos documentos sobre estudos e mapeamentos de áreas de risco em Santa Catarina. 0 ano seguinte é marco para o início de projetos de prevenção e ampliação dos pontos de monitoramento no estado. Em 2017, o Radar Oeste foi implantado em 42\% do território estadual, abrangendo 138 municípios; os Centros Integrados de Gerenciamento de Riscos e Desastres (Cigerds) regionais tiveram suas instalações iniciadas; iniciou-se a fase de testes do Cigerd; Seminários Regionais aconteceram e a Secretaria de Defesa Civil teve sua nova estrutura organizacional aprovada (Moratelli, 2018).

A Secretaria de Estado da Defesa Civil é composta por quatro diretorias: Diretoria de Gestão Administrativa e Financeira; Diretoria de Gestão de Desastres; Diretoria de Gestão de Educação; e Diretoria de Gestão de Risco. Além dos gabinetes do Secretário e Secretário Adjunto. A Lei Complementar no 741, de 12 de junho de 2019, dispõe sobre a estrutura organizacional básica e o modelo de gestão da Administração Pública Estadual (Assembleia Legislativa de Santa Catarina, 2019). Identifica-se avanços em termos técnicos e científicos, mas sem diminuição dos desastres.

\section{Centralização e tecnificação}

O processo de formação e desenvolvimento da Defesa Civil tem um movimento duplo. Por um lado, a institucionalização; por outro, a centralização. A institucionalização das ações de promoção à defesa dos cidadãos é delegada à Defesa Civil quando da sua criação. Essa centralização prejudica a participação social, um dos princípios da GRD, ou seja, torna inviável a participação da sociedade civil e da comunidade científica na gestão. Algumas situações podem explicar esse fato, como o artigo 22 da Constituição Federal de 1988 estabelece em seus incisos III e XXVIII que "Compete privativamente à União legislar sobre: [...] III requisições civis e militares, em caso de iminente perigo e em tempo de guerra; [...] XXVIII - defesa territorial, defesa aeroespacial, defesa marítima, defesa civil e mobilização nacional” (Brasil, 1988, Art. 22º, III e 
XXVIII). $O$ disposto neste artigo pode confundir a competência de legislar com centralizar. Visto que as ações que visam a estabelecer uma gestão, acabam por centralizá-la.

No que concerne à centralização, a Lei no 12.608 de 2012 define que o órgão central de coordenação das ações de proteção e DC no território nacional é a Secretaria Nacional de Proteção e Defesa Civil (Sepdec) (Brasil, 2012). A Lei fala em coordenação, mas a interpretação da lei pode fazer incorrer no mesmo movimento de centralização proporcionado pela interpretação da Constituição Federal de 1988. A centralização da Defesa Civil é uma realidade, bem como sua militarização. Os que defendem a militarização argumentam que o Estado necessita de poder de polícia na gestão do risco de desastres. Para Meireles (2009), esse é o instrumento essencial para frear os abusos cometidos contra os direitos individuais e de segurança da coletividade. Conforme o autor, é o poder de polícia que delimita os limites entre o direito individual e o direito coletivo. No entanto, a DC não necessita de poder de polícia, visto essa instituição já existir e atuar tanto em situações de normalidade ou anormalidade (em caso de desastres).

Contudo, no mundo todo, conforme Moreira (2011), a estrutura da Defesa Civil sempre esteve ligada às instituições militares. No Brasil, em alguns estados, como em Santa Catarina, a Defesa Civil foi gestada na égide das Polícias Militares estaduais. O Corpo de Bombeiros Militar de Santa Catarina (CBMSC) foi criado, em 1919, como um segmento da Polícia Militar (PM). Todavia, o efetivo início das atividades data de 1926. A emancipação da PM ocorre no dia 03 de junho de 2003 (Ascom, 2019). A atuação do CBMSC geralmente se dá na resposta às situações de emergência: ações de socorro, de assistência às vítimas e de restabelecimento. Desde a sua criação, o CBMSC atuou em ações com a Defesa Civil, no estado. São 84 anos de auxílio mútuo no gerenciamento das situações de crise.

A Defesa Civil em Santa Catarina foi instituída em 1973. Primeiro, enquanto Coordenadoria Estadual de Defesa Civil (Cedec), vinculada ao Gabinete da Casa Civil (diretamente ligada ao governador do estado). Depois, como Departamento Estadual vinculado à Secretaria Executiva da Justiça e Cidadania e à Secretaria de Estado da Segurança Pública e Defesa do Cidadão, até 2011 (Defesa Civil de Santa Catarina, 2011). Durante os primeiros 38 anos de existência, a Defesa Civil estadual teve doze coordenadores, todos coronéis da PM. Com a Lei Complementar no 534, de 20 de abril de 2011, passa à Secretaria de Estado da Defesa Civil e, até 2018, teve três secretários, sendo um deles Coronel da PM (Panceri, 2019). Em 2020, assumiu um novo secretário, também Coronel (Defesa Civil de Santa Catarina, $s / d$ ). A Sede da Secretaria de Defesa Civil, bem como toda sua estrutura, localiza-se na capital de Santa Catarina, Florianópolis, bem como o Centro Integrado de Gerenciamento de Riscos e Desastre (Cigerd) que também sedia o Gabinete de Crise da Defesa Civil. Ao todo são vinte Cigerds regionais (Panceri, 2019) no acompanhamento, planejamento e implementação das estratégias de gestão da instituição no estado.

Quando se fala em tecnificação da Defesa Civil, estamos pensando exatamente nisso, na formação de equipes técnicas e todo aparelhamento tecnológico. 0 que pode ser positivo e negativo, ao mesmo tempo. Positivo pela possibilidade de se aprimorar procedimentos, qualificar análises, monitoramento, informação e ação. Negativo quando a técnica não reduz a vulnerabilidade ao risco de desastres, não reduz o impacto ou, ainda, o intensifica. Quando existe uma "assimetria de acesso às informações, às tecnologias adaptativas", o não-acesso ou a não-compreensão da informação, e a população "é induzida a pensar que se encontra protegida pela competência [...] e pela qualidade das especificações técnicas" (Valêncio et al., 2009, p. 149). A tecnificação pode contribuir muito para a redução do risco e da perda de vidas por desastres, mas também pode acontecer de "a ciência e as tecnologias modernas" estarem "diretamente envolvidas na produção do risco, contribuindo para a produção e a legitimação de riscos modernos" (Valêncio et al., 2009, p. 149). Neste sentido, o lado negativo da tecnificação.

Vê-se que a Defesa Civil de Santa Catarina possui todo arcabouço institucional, de estrutura organizacional e técnica para o exercício da GRD como preconizam o Marco de Ação de Hyogo e de Sendai. A GRD é entendida pela EIRD/ONU (UNISDR, 2009, p. 18) como sendo

[...] o conjunto de decisões administrativas, de organização e de conhecimentos operacionais desenvolvidos por sociedades e comunidades para implementar políticas, estratégia e fortalecer suas 
capacidades a fim de reduzir os impactos de ameaças naturais e de desastres ambientais e tecnológicos consequentes. Isto envolve todo o tipo de atividades, incluindo medidas estruturais e não estruturais para evitar (prevenção) ou limitar (mitigação e preparação) os efeitos adversos dos desastres.

Significa que a proposta da GRD, diferentemente da proposta de GD, é de um sistema descentralizado de gestão e para que isso ocorra não pode haver centralização de ações. Se o processo decisório tem por objetivo fortalecer a capacidade de redução dos impactos das ameaças da própria sociedade ou comunidade que o implementa, esse processo precisa ser descentralizado.

A própria Defesa Civil de Santa Catarina prevê e atua com um sistema descentralizado de gestão quando elenca quatro princípios a serem seguidos na gestão de uma crise: 1) ferramenta de gestão de desastre, compartilhado num ambiente próprio, desenhado ou mesmo improvisado, para comportar a administração de uma crise; 2) ações e decisões são multidisciplinares e multissetoriais; 3) 0 necessário e suficiente para o máximo de pessoas, no mínimo espaço de tempo possível; e 4) as ações devem prever as necessidades técnicas, atendendo às expectativas sociais, com a participação do ente político envolvido na solução da crise. Esses princípios demonstram que coordenar ações de gestão de crise não é centralizar o processo decisório. No gerenciamento da crise as decisões devem ser tomadas em conjunto. Decisões hierarquizadas ignoram a participação social (comunidade científica e local) e mantêm o monopólio das ações restritas às coordenadorias (Secretaria de Estado da Defesa Civil, 2017).

\section{Considerações Finais}

O artigo aborda a questão da gestão dos desastres no Brasil, com base no estudo de caso da Defesa Civil de Santa Catarina. Tem como argumento central que quanto maior a centralização e a tecnificação, menor a coordenação e mais burocrática a gestão. Gestões burocráticas ignoram algumas premissas dos Marcos de Hyogo e Sendai para a GRD em substituição à GD. E a tecnificação pode ter impacto, tanto negativo como positivo no controle do risco de desastres. Pode ser positivo, pois promove o aprimoramento de mecanismos para monitorar o risco, assim como qualifica os procedimentos para a ação no trans e pósimpacto. Pode ser negativo, por dar uma falsa sensação de segurança para a população e ocultar os limites relacionados à qualidade das especificidades técnicas.

Metodologicamente, o texto é de cunho qualitativo, bibliográfico, teórico-empírico e exploratório. Exploratório, pela escassez de estudos na temática específica da gestão dos desastres no Brasil e história da DC em Santa Catarina. Inicia com um panorama dos desastres no mundo e a história da pesquisa na área. Diferencia a GD da GRD possibilitando a compreensão da crítica e argumento central do estudo, além de que explicita a necessidade de mudanças na gestão dos desastres no Brasil para que uma efetiva GRD ocorra. A Defesa Civil de Santa Catarina constitui o tema central do artigo. Uma análise de sua história, territorialização, institucionalização e atuação é realizada nesse texto a partir de dados fornecidos pela própria instituição.

A Defesa Civil de Santa Catarina prevê e trabalha por um sistema descentralizado de gestão. Esse esforço de descentralização fica explícito quando encontrados os princípios que a instituição elencou para enfrentar a crise. Neles fica claro que há uma busca por ações e decisões multidisciplinares e multisetoriais, dando a entender que a sociedade civil e a comunidade científica podem ter espaço garantido nos processos decisórios da gestão da crise. No entanto, a participação social na gestão deve ocorrer também em tempos de normalidade. Um dos objetivos do processo decisório é fortalecer a capacidade de resiliência de um sistema ou comunidade e reduzir o impacto do evento sobre a própria sociedade. Mais do que necessário que a sociedade participe deste processo, mas para que isso seja possível, a descentralização precisa ser mantida e fortalecida. A Defesa Civil precisa de coordenação e não de centralização. A descentralização deve ser concebida e articulada com o aumento da capacidade de autoproteção individual das pessoas e comunitária. 


\section{Referências}

Albtoush, R., Dobrescu, R., \& Ionescou, F. (2011). A hierarchical model for emergency management systems. U.P.B. Sci. Bull., Series C, 73(2), 53-62. Recuperado em 05 de agosto de 2017, de http://www.scientificbulletin.upb.ro/rev_docs/arhiva/full87242.pdf.

Assembleia Legislativa de Santa Catarina (2011, 20 de abril). Lei no 534, de 20 de abril de 2011. Florianópolis, SC. Recuperado em 05 de maio de 2021, de http://leis.alesc.sc.gov.br/html/2011/534_2011_Lei_complementar.html.

Assembleia Legislativa de Santa Catarina (2014, 24 de junho). Lei n. 16.418, de 24 de junho de 2014. Florianópolis. Recuperado em 03 de março de 2019, de http://leis.alesc.sc.gov.br/html/2014/16418_2014_Lei.html.

Assembleia Legislativa de Santa Catarina (2019, 12 de junho). Lei Complementar № 741, de 12 de junho de 2019. Florianópolis, SC. Recuperada em 09 de novembro de 2020, de http://leis.alesc.sc.gov.br/html/2019/741_2019_lei_complementar.html.

Amin, S., \& Goldstein, M. (2008). (Org). Data against disasters: establishing effective systems for relief, recovery, and reconstruction. Washington DC: The World Bank.

Ascom. (2019). CBM 93 anos: história quase centenária dos heróis do fogo... Recuperado em 10 de setembro de 2019, de http://www.ssp.sc.gov.br/index.php/component/content/article/87-noticias/793-cbm-93-anos-historia-quasecentenaria-dos-herois-do-fogo.

Asghar, S., Alahakoon, D., \& Churilov, L. (2011). A Comprehensive Conceptual Model for Disaster Management. Clayton School of Information Technology, Monash University, Australia. Recuperado em 05 de agosto de 2019, de http://sites.tufts.edu/jha/files/2011/04/a193.pdf.

Assunção, V. K. de. (2014). Enchente de 1974 como drama social: relações entre percepção de risco, conflito e gentrificação. Ambiente \& Sociedade, São Paulo, 17(4), 195-212. https://doi.org/10.1590/1809-4422ASOC1109v1742014.

Avila, M. R. R., \& Mattedi, M. A. (2017). Desastre e território: a produção da vulnerabilidade a desastres na cidade de Blumenau/SC. urbe. Revista Brasileira de Gestão Urbana [online], 9(2), 187-202. http://dx.doi.org/10.1590/21753369.009.002.ao03.

Brasil (1988, 05 de outubro). Constituição Federal de 1988. Recuperado em 10 de março de 2017, de https://www.senado.leg.br/atividade/const/con1988/con1988_18.02.2016/art_22_.asp.

Burton, I., Kates, R. W., \& White, G. F. (1993). The environment as hazards. New York: The Guilford Press.

Câmara Municipal de Tubarão (1973, 16 de outubro). Decreto n. 253 de 16 de outubro de 1973. Tubarão, SC. Recuperado em 09 de novembro de 2020, de https://camara-municipal-do-tubarao.jusbrasil.com.br/legislacao/807832/decreto-253-73\#.

Câmara Municipal de Blumenau (1973, 20 de dezembro). Lei no 1.981, de 20 de dezembro de 1973. Blumenau, SC. Recuperado em 05 de maio de 2021, de https://leismunicipais.com.br/a/sc/b/blumenau/leiordinaria/1973/198/1981/lei-ordinaria-n-1981-1973-cria-o-sistema-de-defesa-civil-no-municipio-e-da-outrasprovidencias.

Câmara Municipal de Blumenau (2013, 01 de janeiro). Lei Complementar no 870, de 01 de janeiro de 2013. Blumenau, SC. Recuperado em 05 de maio de 2021, de https://leismunicipais.com.br/a/sc/b/blumenau/leicomplementar/2013/87/870/lei-complementar-n-870-2013-estabelece-nova-estrutura-administrativa-do-poderexecutivo-municipal-de-blumenau-e-da-outras-providencias

Carr, L. J. (1932). Disaster and the Sequence-Pattern Concept of Social Change. American Journal of Sociology, 38(2), $207-218$.

Centro de Estudos e Pesquisas em Engenharia e Defesa Civil - CEPED. (2015). 2004 - Furacão Catarina. Publicado em 05/08/2015. Grandes Desastres, UFSC, Florianópolis, SC. Recuperado em 14 de fevereiro de 2019, de http:

//www.ceped.ufsc.br/2004-furacao-catarina/.

Confederação Nacional de Municípios - CNM. (2015). Proteção e Defesa Civil em âmbito Local: Conceitos e Competências. Brasília: CNM, 2015.

Brasil - Congresso Nacional (2012, 20 de abril). Lei n. 12.608, de 20 de abril de 2012. Dispõe sobre o Sistema Nacional de Proteção e Defesa Civil - SINPDEC e o Conselho Nacional de Proteção e Defesa Civil - CONPDEC. Presidência da República, Casa Civil, Subchefia para Assuntos Jurídicos. Brasília, DF. Recuperado em 03 de novembro de 2017, de http://www.planalto.gov.br/ccivil_03/_ato2011-2014/2012/lei/l12608.htm. 
Defesa Civil de Blumenau. ( $s / d$ ). Histórico. Governo, Secretaria da Defesa do Cidadão. Blumenau. Recuperado em 18 de fevereiro de 2019, de https://www.blumenau.sc.gov.br/secretarias/secretaria-de-defesa-do-cidadao/pagina/historicodefesa-cidadao.

Defesa Civil de Itajaí - DC Itajaí. (s/d). Histórico: a criação da Defesa Civil de Itajaí. Publicado no site da Defesa Civil de Itajaí. Recuperado em 10 de março de 2019, de https://defesacivil.itajai.sc.gov.br/c/historico.

Defesa Civil de Santa Catarina. A Secretaria. Publicado em 14 dezembro de 2011, às 18h34min. Institucional. Defesa Civil Santa Catarina, Florianópolis, SC. Recuperado em 19 de fevereiro de 2019, de http://www.defesacivil.sc.gov.br/index.php/institucional/a-secretaria.html.

Defesa Civil de Santa Catarina. (s/d). Biografia do Chefe da Defesa Civil de SC. Publicado em Institucional. Defesa Civil Santa Catarina, Florianópolis, SC. Recuperado em 03 de novembro de 2020, de https://www.defesacivil.sc.gov.br/institucional/biografia-do-chefe-da-defesa-civil-de-sc/

The International Disaster Database. (2020). Centre for Research on the Epidemiology of Disaster (CRED). Bruxelas, Bélgica. Recuperado em 03 de maio de 2020, de https://www.emdat.be/.

Gall, M., Nguyen, K. H, \& Cuuet, S. L. (2015). Integrated research on disaster risk: is it really integrated? International Journal of Disaster Risk Prevention, 12, 255-267. https://doi.org/10.1016/j.ijdrr.2015.01.010.

Guha-Sapir, G., Below, R., \& Hoyois, P. (2015). EM-DAT: The OFDA/CRED International Disaster. Data base. Recuperado em 18 de abril de 2017, de http://www.emdat.be/disaster_trends/index.html.

Herrmann, M. L. de P., Marimon, P., Lopes, P., Machado, S. M., Zabot, C., Cerew, T. H., \& Cristo, S. V. de. (s/d). Desastres naturais no estado de Santa Catarina-BR associados ao fenômeno climático global El Niño durante período 1980-2000. UFSC/UDESC, Florianópolis. Recuperado em 10 de março de 2019, de http://observatoriogeograficoamericalatina.org.mx/egal8/Procesosambientales/Climatologia/01.pdf.

International Strategy for Disaster Reduction. (2005). Hyogo Framework for Action 2005-2015. Building World Conference on Disaster Reduction, Kobe, Hyogo, Japan. 18-22. Recuperado em 05 de maio de 2021, de https://www.unisdr.org/2005/wcdr/intergover/official-doc/L-docs/Hyogo-framework-for-action-english.pdf.

Joner, K. Linha do Tempo da Defesa Civil em Santa Catarina, 2019. Não publicado.

Marandola Jr. E. \& D’antona, A. de O. (2014). Vulnerabilidade: problematizando e operacionalizando o conceito. In: Carmo, R., \& Valêncio, N. (pp. 45-61) Segurança humana no contexto de desastres. São Carlos: RiMa Editora.

Massignam, A. M., Pandolfo, C., Ricce, W. da Silva., Vieira, H. J., \& Braga, H. J. (2016). A agrometeorologia operacional em Santa Catarina. Agrometeoros, Passo Fundo, 24(1), 55-63. Recuperado em 09 de novembro de 2020. http://dx.doi.org/10.31062/agrom.v24i1.24881.

Mattedi, M. A. (2015). Pensando com o desenvolvimento regional: subsídios para um programa forte em desenvolvimento regional. Revista Brasileira de Desenvolvimento Regional - RBDR, 2(2), 59-105.

Mattedi, M. A., \& Butzke, I. C. (2001). A Relação entre o social e o natural nas abordagens de hazards e de desastres. Ambiente \& Sociedade, (9), 10-21. https://doi.org/10.1590/S1414-753X2001000900006.

Meireles, H. L. (2009). Direito Administrativo Brasileiro. São Paulo: Malheiros.

Moratelli, R. A. F. F. S. (2018). Santa Catarina resiliente, 10 anos após o desastre de 2008. In 2º Seminário Internacional de Proteção e Defesa Civil. Florianópolis, SC/Brasil. Recuperada em 08 de novembro de 2020, de https://www.youtube.com/watch?v=wJCkRbX4TmQ\&ab_channel=UnisulVirtual.

Moreira, N. X. (2011). Instituições militares: uma análise sociológica. Rio de Janeiro. Recuperado em 06 de março de 2019 , de https://www.marinha.mil.br/dasm/sites/www.marinha.mil.br.dasm/files/Institui\%C3\%A7\%C3\%B5es\%20Militares.pdf.

Montz, B. E., \& Tobin, G. A. (2011). Natural hazards: evolving tradition in applied geography. Applied Geography, 31, 14. https://doi.org/10.1016/j.apgeog.2010.06.005.

Narváez, L., Lavell, A., \& Ortega, G. P. (2009). La gestión del riesgo de desastres: um enfoque basado en procesos. Proyecto Apoyo a la Prevención de Desastres en la Comunidad Andina - Predecan. 1. ed., Lima, 106 p.

Organização das Nações Unidas (2005). Informe de la Conferencia Mundial sobre la Reducción de los Desastres. Conferencia Mundial sobre la Reducción de los Desastres, em 18 a 22 de enero de 2005. Kobe, Hyogo (Japón). 
Organização das Nações Unidas (2015). Marco de Sendai para a Redução do Risco de Desastres 2015-2030. In III Conferência Mundial sobre a Redução do Risco de Desastres, realizada de 14-18 março de 2015, em Sendai, Miyagi, no Japão.

Ostrom, E. (2010). Polycentric Systems for Coping with Collective Action and Global Environmental Change. Global Environmental Change, 20, 550-557. https://doi.org/10.1016/j.gloenvcha.2010.07.004

Ostrom, V. (1999). Polycentricity - Part I. In Ginis, M. M. (Ed.). Polycentricity and Local Public Economics. (p. 52-74). Ann Arbor: University of Michigan Press.

Panceri, R. (2019). Informações Defesa Civil Sc - Artigo Furb. Florianópolis, SC.

Pelanda, C. (1981). Disaster and sociosystemic vulnerability. Newark: Preliminary Paper \#68 — Disaster Research Center/University of Delaware. 1-24. Recuperado em 05 de maio de 2021, de https://udspace.udel.edu/bitstream/handle/19716/440/PP68.pdf?sequence=3\&isAllowed=y.

Perry, R. W., \& Quarantelli, E. L. (2005). What is a disaster? New answers to old questions. Bloomington: Xlibris.

Prince, S. H. (1920). Catastrophe and social change: based upon a sociological study of the Halifax disaster (Doctoral dissertation). Columbia University, Department of Political Science. Recuperado em 05 de maio de 2021, de https://www.gutenberg.org/files/37580/37580-h/37580-h.htm.

Quarantelli, E. L. (1994). Disasters and catastrophes: their roots in and consequences for social change. Não publicado.

Quarantelli, E. L., Dynes, R. (1977). Response to Social Crisis and Disaster. Annual Review of Sociology, 3, 2349. https://www.annualreviews.org/doi/10.1146/annurev.so.03.080177.000323.

Queiroz, A. D. (2009) Prefácio. In Frank, B., \& Sevegnani, L. (Orgs.). Desastre de 2008 no Vale do Itajaí: água, gente e política (p. 8-9). Blumenau: Agência de Água do Vale do Itajaí.

Secretaria de Estado da Defesa Civil. (2017). Gestão de Riscos e Gestão de Desastres. Florianópolis, SC. Defesa Civil. 160.

United Nations International Strategy for Disasters Reduction. Terminology on Disaster risk reduction. (2009). Geneva, Switzerland. 30. Recuperado em 09 de novembro de 2020, de https://www.unisdr.org/files/7817_UNISDRTerminologyEnglish.pdf

Valêncio, N., Siena, M., Marchezini, V., \& Gonçalves, J. C. (Org.). (2009). Sociologia dos desastres: construção, interfaces e perspectivas no Brasil. São Carlos: RiMa Editora.

Vieira, H. J. (2019). Informações Epagri/Ciram E Defesa Civil/Sc. Recebido em: 25 fev. 2019, às 15h27min. Florianópolis, Santa Catarina. Recebido por e-mail.

Walker, J. M., Gardner, R., Herr, A., \& Ostrom, E. (2000). Collective Choice in the Commons: Experimental Results on Proposed Allocation Rules and Votes. The Economic Journal, 110, 212-234. https://doi.org/10.1111/1468-0297.00497

Wenger, D. (1978). Community response to disaster. In Quaranteli, E. L. (Ed.), Disasters: Theory and Research. (p. 17-47). Bervely Hills CA: Sage.

White, G. F. (1973). Natural hazards research. In Chorley, R. J. (Ed.), Directions in Geography (193-216). London: Methuen \& Co.

White, G. F. (1974). Natural hazards research: concepts, methods and policy implications. In White, G. F. Natural hazards: local, national, global. (p. 3-16). New York: Oxford University.

Zenatti, A. P. de, \& Souza, S. Y. U. de (Orgs). (2009). Relatos de um Desastre - Narrativas Jornalísticas da Tragédia de 2008 em Santa Catarina. Governo do Estado de Santa Catarina / Secretaria Executiva da Justiça e Cidadania / Departamento Estadual de Defesa Civil. Florianópolis: UFSC/CEPED.

Editor: Fábio Duarte

Recebido: 11 mar. 2020

Aprovado: 14 abr. 2021 